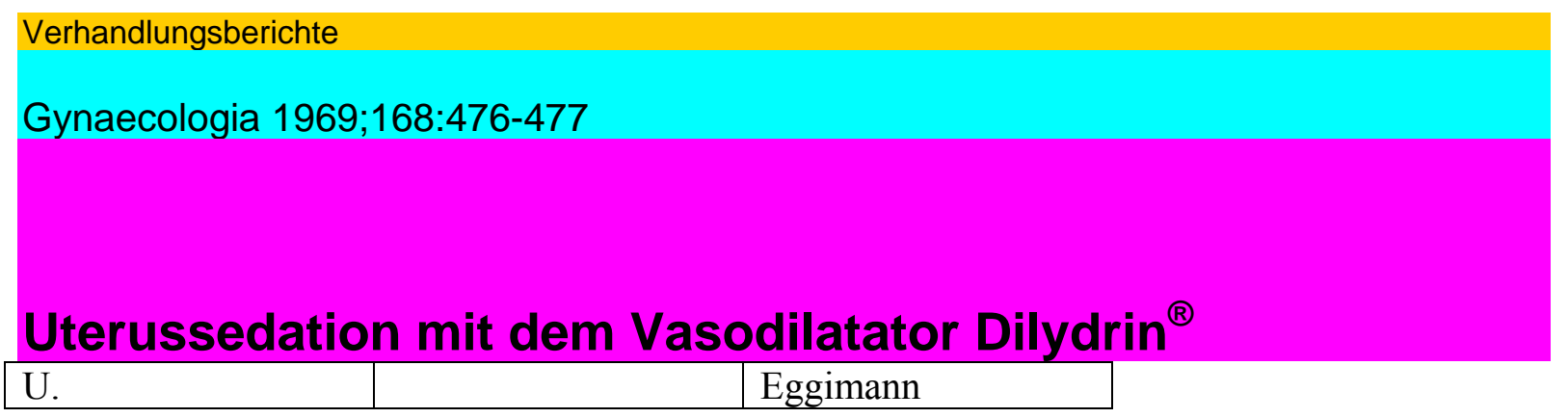

Universitätsklinik Bern (Direktor: Prof. M. Berger)

Adresse des Autors: Dr. Urs Eggimann, Bezirksspítal Bíel, CH-2500 Biel (Schweiz)

Dilydrin ${ }^{\circledR}$, in Deutscbland als Dilatol ${ }^{\circledR}$ bekannt, wird in der innern Medizin als Vasoldilatator und «Kreislaufaktivator» verwendet.

1967 erschienen mehrere Publikationen aus der Universitätsklinik Giessen (Kepp, Wolff, Bailer) über die gute wehenhemmende Wirkung des Dilydrins ${ }^{\circledR}$ bei drohender Früh- und Fehlgeburt. Chemísch bandelt es sich urn ein Katecholaminderivat (aus der Adrenalingruppe), bei welchem die sympatikomimetische, gefäss-kontrahierende Wirkung durch Substitution der freien Amine in eine gefässdilatierende umgewandelt wurde.

Cretíus, Zímmermann und Staníenda aus Würzburg verglichen Dilydrin ${ }^{\circledR}$ (Buphenin-HCl) und Duvadilan ${ }^{\circledR}$ (Isoxsuprin Hydro-chlorid), ein nahe verwandtes Präparat, wobei ersteres bei einer Do-sierung, die gleich starke Nebensymptome auslöst, einen etwas bessern wehenhemmenden Effekt aufwies.

In der Mehrzahl meiner 20 Fälle ist die Wehenhemmung rascb und vollständig aufgetreten. Unsere Indíkatíonen. 1. Geburtsbeginn bei drohender Frühgeburt. 2. Blutung bei Präviaverdacht. 3. Abortus imminens bei nachweis-baren Herztönen. 4. Prä- und postoperative Uterussedation bei Cerclageoperation.

Dosierung. Wir halten uns im Prinzip an das Giessenerschema. Dabei steigere ich die Dosis bis zum Eintritt der Wehenhemmung und der Nebensymptome individuell.

Zur Techník. Wir messen die Wehenaktivität während mindestens 30 min vor Behandlungsbeginn mit externer Tokographie (Mod. Vaquum Extraktor, Malmö). Wir erhalten dabei keine absoluten Werte der Wehenarbeit, aber zum Verfolgen des Einzelfalls vor und während der Behandlung, unter konstanten Bedingungen, darf die externe Tokographie angewendet werden. Analog den bei interner Tokographie verwendeten Montevideoeinheiten, habe ich eine modifizierte Einheit definiert. Mod. Mont. E: : mittl. externer Wehenaus-

\title{
, Frequenz
}

schlag $\times--$ - $-10 \mathrm{~mm}$

Eggímann, Uterussedation mit dem Vasodilatator Dilydrin 477

Während der Infusion verbleibt der Patient in Seitenlage, um ein Robertsonphänomen zu verhindern und steht unter intensiver Über-wachung.

Eígene Fälle

Fall 3. L. M. 19jährige I-Para tritt 8 Wochen vor Termin mit We-hen und Blutung wegen Präviaverdacht ein.

$10 \mathrm{mg}$ Dilydrin ${ }^{\circledR}$-Infusion zeigt keine Wirkung. Steigerung der Infusion auf $40 \mathrm{mg}$ innerhalb $2 \mathrm{~h}$ $15 \mathrm{~min}$. 
Wirkung: Nach 2 h Pulsanstieg von +45 und Abfall des diasto-lischen Blutdrucks von 80 auf 10 mm Hg. Subjektiv: starkes Angst-und Herzgefühl. Wehenfrequenz nimmt ab.

Fall 4. A. G.-Z. 25jährige П-Para tritt wegen Wehen in der 30. -32. SSW ein (niedrige Amplitude, hohe Frequenz). Infusion von $10 \mathrm{mg}$ Dilydrin ${ }^{\circledR}$.

Wirkung: Amplitude bleibt konstant. Frequenz nimmt ab und verschwindet ganz. Keine Begleitsymptome.

Mobilisation und ambulante Nachbehandlung gemäss Schema. Ge-burt nach 55 Tagen, eingeleitet durch künstliche Blasensprengung.

Fall 8. M. Sch.-J. 25jährige I-Para war wegen leichter Blutung ab 28. SSW 4 Wochen auswärts hospitalisiert. Wegen verstärkter Blutung und Präviaverdacht Verlegung ins Frauenspital mit leichten Wehen, mässig starker Blutung und Abgang von Koagula. Infusion von $10 \mathrm{mg}$ Dilydrin ${ }^{\circledR}$.

Wirkung: Nach 7,65 mg Dilydrin ${ }^{\circledR}$ wird die Blutung schwächer, parallel mit einer Tachykardie von +56 . Wehenfrequenz nimmt ab und ist am Ende der Infusion $=0$.

Nach 15 Tagen erneute Blutung. Diese geht unter der Infusion parallel mit dem diastolischen Blutdruckabfall zurück.

Geburt. Nach 16 Tagen eingeleitet durch künstliche Blasensprengung in der 35. SSW. Gesundes Mädchen $2180 \mathrm{~g} / 45 \mathrm{~cm}$, Apgar 8/10.

Wir steigern die Dosierung kontinuierlich, bis Nebensymptome auftreten, die Wehenhemmung kommt meist gleichzeitig oder kurz darauf.

Die Nebensymptome Tachycardie, Blutdruckabfall und Herzklopfen sind harmlos und gehen nach Abstellen der Infusion rasch zurück.

Kontraíndíkatíonen. Herz- und Kreislaufkrankheiten

Fieber sub partu genitalen und extragenitalen Ursprungs. 